\title{
SNMMI and EANM guidelines for diuretic renography in children
}

\author{
Diego De Palma
}

Received: 4 September 2014 / Accepted: 9 September 2014 /Published online: 16 September 2014

(C) Springer-Verlag Berlin Heidelberg 2014

\section{Dear Sir,}

I read the interesting letter by De Man K al. [1]. It is true that there are discrepancies between the SNMMI [2] and EANM [3] guidelines for diuretic renography in children. Both we and our North American colleagues are aware of this problem, and the SNMMI and EANM paediatric committees began to discuss harmonisation a couple of years ago, starting with the injected activities. The goal of having common guidelines for all procedures is drawing closer to realisation with every day that passes; indeed, we expect to begin publishing common updated guidelines next year. Coming to letter, I would like to comment on the background to the guidelines and to address differences in respect of hydration and catheterisation. First, it must be underlined that the SNMMI guidelines (whose newest reference date is 2006) are more technically driven (and were published in the J Nucl Med Technol), whilst the EANM guidelines are more evidence based/evidence oriented; this probably reflects differences in working organisation. The preference of the SNMMI for intravenous hydration and catheterisation is very likely related to their desire for reproducible mathematical analysis of the drainage pattern. A large body of literature now demonstrates that, even in a highly standardised setting, the positive diagnosis of obstruction is impossible with a single diuretic renogram and can be achieved only during integrated instrumental follow-up. This is why the EANM guidelines suggest the lowest degree of invasiveness (oral hydration and no catheterisation) and the necessity for (and reliability of) the post-micturition acquisition and calculation of output efficiency/normalised residual activity. In conclusion, on behalf of the EANM Paediatric Committee, we still recommend use of our guidelines, in conjunction with continuing clinical cooperation with the referring urologist, which is indispensable.

\section{References}

1. De Man K, Duong HP, Goethals I. Comparison of EANM and SNM guidelines on diuretic renography in children. Eur J Nucl Med Mol Imaging. 2014;41:1815. doi:10.1007/s00259-014-2779-6 .

2. Shulkin BL, Mandell GA, Cooper JA, Leonard JC, Majd M, Parisi MT, et al. Procedure guideline for diuretic renography in children 3.0. J Nucl Med Technol. 2008;36(3):162-8.

3. Gordon I, Piepsz A, Sixt R. Guidelines for standard and diuretic renogram in children. Eur J Nucl Med Mol Imaging. 2011;38(6): $1175-88$.
D. De Palma $(\bowtie)$

Department of Nuclear Medicine, H. Circolo Varese, Viale L. Borri

57, 21100 Varese, Italy

e-mail: didepal@tin.it 